\title{
IMPLEMENTASI AKSES MYSQL DAN WEB SERVER LOKAL MELALUI JARINGAN INTERNET MENGGUNAKAN NGROK
}

\author{
Rizky Parlika ${ }^{1}$, Heri Khariono ${ }^{2}$, Haidar A Kusuma ${ }^{3}$, Merdin R Abrori ${ }^{4}$, Moh. A Rofik ${ }^{5}$ \\ 1,2,3,4,5 Program Studi Teknik Informatika, Fakultas Ilmu Komputer, Universitas Pembangunan Nasional \\ "Veteran" Jawa Timur \\ Email: ${ }^{1}$ rizkyparlika.if@ upnjatim.ac.id, ${ }^{2}$ herikhariono7@gmail.com, ${ }^{3}$ elhaidar45@gmail.com, \\ ${ }^{4}$ merdin.abrori@gmail.com, ${ }^{5} 18081010073 @$ student.upnjatim.ac.id
}

(Naskah masuk: 28 Mei, diterima untuk diterbitkan: 2 September 2020)

\begin{abstract}
Abstrak
Biasanya para pemula menggunakan web hosting untuk meletakkan file-file aplikasi web mereka beserta databasenya. Artinya baik file-file penyusun front end maupun back end diletakkan didalam web hosting. Namun bagaimana bila dilakukan sebuah prosedur dimana hanya databasenya saja yang diletakkan di web hosting dan file-file pengakses database berada di local computer. Hal ini tentu akan mendukung berbagai teknik pengembangan aplikasi di sisi masing-masing lokal pengakses, dimana database yang mereka akses hanya 1 yakni di web hosting. Metode ini akan membantu manakala seorang admin di pusat yang bertindak menyediakan data, dapat memberikan akses tabel kepada beberapa lokal klien pengakses yang tersebar secara geografis. Masingmasing klien dapat menggunakan bahasa pemrograman apa saja yang dikuasainya untuk mengakses database terpusat di sisi admin. Hal ini dapat dilakukan salah satunya dengan memanfaatkan layanan Ngrok. Pada makalah ini akan ditunjukkan langkah demi langkah bagaimana sebuah aplikasi berbasis PHP yang berada pada web server local menggunakan xampp dapat mengakses dan membaca database MySQL pada web hosting. Hasilnya aplikasi dapat berjalan dengan lancar dan terbuka untuk pengembangan yang lebih kompleks.
\end{abstract}

Kata kunci: localhost, MySQL, ngrok, DBMS.

\section{IMPLEMENTATION OF MYSQL ACCESS AND LOCAL WEB SERVER THROUGH THE INTERNET NETWORK USING NGROK}

\begin{abstract}
Usually beginners use web hosting to prepare their web application files with the database. Hope that both the frontend and backend files make up the web hosting. But when a procedure is performed where only the database is placed on web hosting and the database file access is on the local computer. This certainly will support various application development techniques in each local access, while the database they access is only 1 on web hosting. This method will help when the central admin acts to provide data, providing access tables for several local access clients that are distributed geographically. Each client can use whatever programming language it controls to access a centralized database on the admin side. This can be done one of them by using the Ngrok service. In this paper, we will discuss step by step about the appropriate PHP-based application on a local web server using xampp, which can be accessed and read the MySQL database on web hosting. Download applications that can run easily and open for more complex developments.
\end{abstract}

Keywords: localhost, MySQL, ngrok, DBMS.

\section{PENDAHULUAN}

Saat ini, penyimpanan data merupakan suatu hal yang sangat penting [1], seperti halnya internet yang sangat dibutuhkan untuk mendapatkan berbagai informasi. Hal ini disebabkan karena efek dari perkembangan teknologi informasi dan komunikasi yang sangat pesat [2], sehingga menuntut manusia untuk bekerja dan memperoleh informasi dengan waktu sesingkat-singkatnya, namun dengan informasi yang semaksimal mungkin [3].

Penggunaan website dalam mengungkapkan informasi sangatlah membantu dan berguna bagi lembaga-lembaga atau perusahaan-perusahaan[4], [5]. Untuk itu perlu adanya MySQL agar dapat mengolah dan melakukan manajemen data [6], dan untuk mendapatkan berbagai informasi yang dibutuhkan melalui sebuah web yang nantinya web 
tersebut akan dicari oleh web browser, sehingga itu semua perlu adanya web server menjadi sebuah host berbagai aplikasi web, baik pada lingkungan internet maupun lokal yg bertujuan memudahkan konfigurasi manajemen web site, dan mail. Sehingga Web browser dan tunnel Ngrok sehingga monitoring dapat dilakukan dengan jaringan yang berbeda [7]. Ngrok sendiri dapat membantu membuat bagian dengan aman serta memberikan URL server [8].

MySQL adalah basis data yang paling terkenal di kalangan insinyur perangkat lunak web, dengan alasan bahwa program ini bisa menjadi basis data yang sangat solid dan cukup baik untuk digunakan sebagai media kapasitas informasi. Sebagai server basis data yang dapat mengawasi basis data secara sah, mysql merupakan basis data yang paling banyak digunakan dibandingkan dengan basis data lainnya. Dalam ekspansi ke mysql masih ada beberapa jenis server database yang juga memiliki kemampuan yang lebih dari itu tidak dapat dianggap sederhana [9].

Agar dapat bekerja dengan server database, diperlukan Hypertext Preprocessor atau PHP. PHP sendiri dibuat sedemikian rupa sehingga pembuatan dokumen HTML yang dapat mengakses database menjadi begitu mudah [11], [12]. PHP merupakan bahasa pemrograman yang berbentuk skrip yang diletakkan di server dan disiapkan di server. Pesan dikirim ke klien, tempat klien menggunakan browser. Dengan memanfaatkan PHP, situs akan lebih intuitif dan energik [13], [14].

Sedangkan, untuk menyimpan dokumendokumen di web dibutuhkan sebuah server web, dimana komputer ini akan melayani permintaan dokumen web dari kliennya. Browser web berkomunikasi melalui jaringan dengan server web, menggunakan protokol HTTP. Browser akan mengirim request kepada server untuk meminta

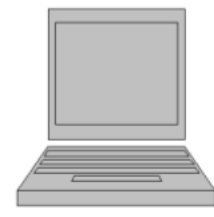

Browser web

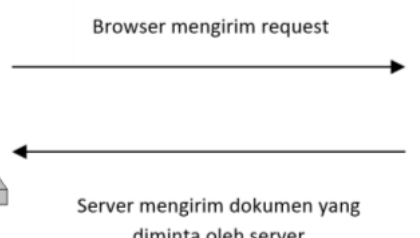

diminta oleh server

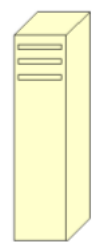

Server web dokumen tertentu atau layanan lain yang disediakan oleh server yang kemudian akan di kirim oleh server dalam bentuk HTML [15].

Gambar 1. Konsep dasar web server [15]

Dalam penelitian ini sistem dirancang menggunakan bahasa pemrograman PHP dan database Mysql. Hal ini bertujuan untuk mempermudah proses yang digunakan, sehingga dapat dilakukan dengan cepat [16], serta menggunakan layanan Ngrok untuk mengakses MySQL dan web server yang menggunakan jaringan internet.

\section{METODE PENELITIAN}

Penelitian ini dilakukan untuk mengakses MySQL dan Web Server menggunakan layanan nggrok agar dapat berjalan dengan lancar. adapun tahapan yang dilakukan dalam penelitian ini yaitu persiapan data, alur pelaksanaan sistem, pemecahan masalah, dan simulasi pelaksanaan sistem

Tahapan pertama adalah persiapan data dan website tahap ini penting dilakukan karena pada saat melakukan pengaksesan dilakukan dalam website dan menggunakan data di mysql. Tahapan kedua adalah membuat alur pelaksanaan sistem atau flowchart diagram, tahap ini digunakan untuk memperjelas dan untuk memudahkan pemahaman sistem yang nantinya akan dijalankan. Tahapan ketiga adalah membuat fishbone diagram yang digunakan untuk memecahkan atau mengatasi permasalahan pada sistem. Tahapan terakhir adalah simulasi pengaksesan mysql dan web server lokal pada komputer lain menggunakan layanan ngrok.

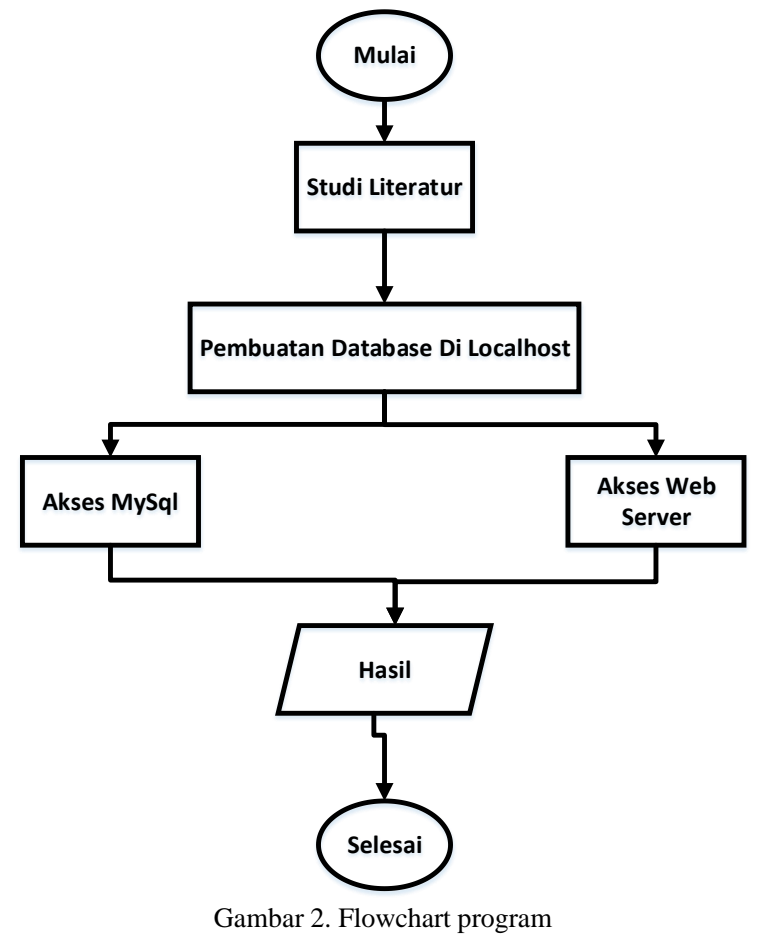

Pada gambar tersebut menjelaskan tentang mulai langkah-langkah awal pelaksanaan program sampai akhir pelaksanaan program. Diawali dengan studi literatur untuk menyimpulkan kebutuhan sistem pada program yang akan dibuat. Langkah selanjutnya adalah pembuatan database mysql pada server lokal yang nantinya akan dihubungkan dengan ngrok. Pada tahap berikutnya mengakses database mysql dan web server, sehingga database yang telah dibuat disambungkan dengan ngrok agar dapat diakses pada perangkat lain. Hasilnya pada implementasi ngrok tersebut yaitu perangkat lain dapat mengakses server lokal dan database pada mysql yang telah dibuat sebelumnya tanpa menggunakan layanan web hosting. 


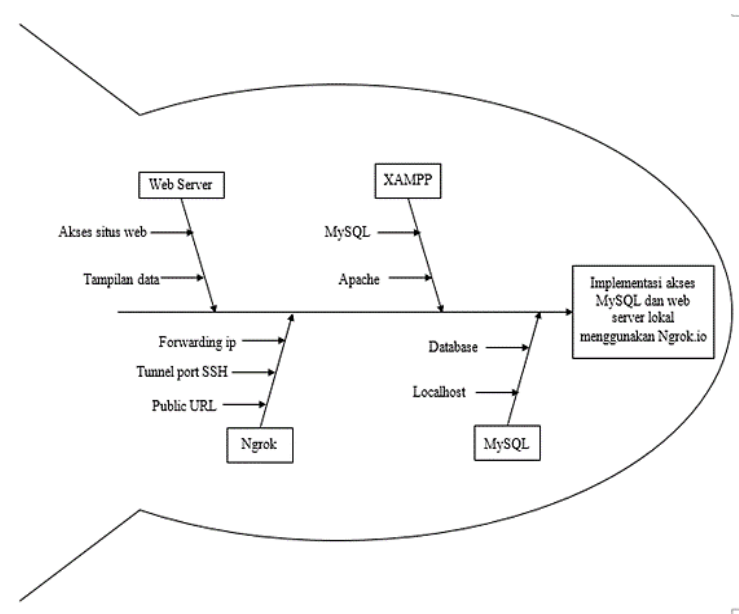

Gambar 3. Diagram fishbone

Pada Gambar 3 menjelaskan tentang bagaimana cara menyelesaikan masalah untuk

\section{HASIL DAN PEMBAHASAN}

Pada bab hasil penelitian dan pembahasan ini dapat diketahui langkah-langkah pengaksesan dari sistem yang sudah dirancang pada bab sebelumnya. Tujuan dari hasil penelitian dan pembahasan sistem adalah untuk mengetahui proses pengaksesan localhost yang berada pada komputer lain dengan menggunakan layanan nggrok dari sistem secara satu persatu maupun secara keseluruhan sistem. mengimplementasikan akses mysql dan web server lokal menggunakan layanan ngrok.

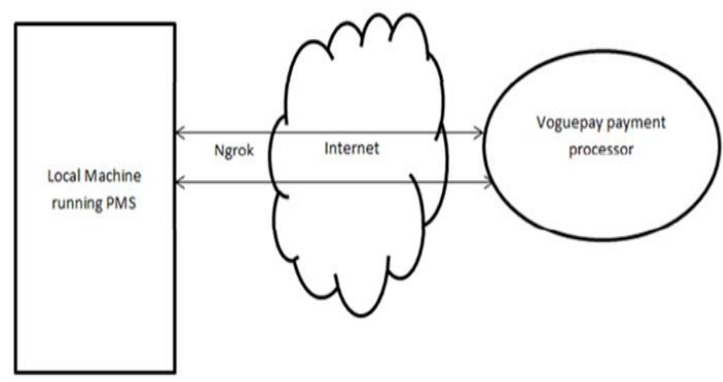

Gambar 4. Simulasi ngrok[17]

Gambaran proses ngrok dapat dilihat pada Gambar 4, proses dimana dengan menggunakan ngrok dan terhubung jaringan internet dapat mengakses localhost pada komputer yang akan dituju.

Pengujian kinerja sistem dan keseluruhan sistem didasarkan pada perancangan sistem. Hasil dari pengujian akan digunakan sebagai dasar untuk menentukan kesimpulan, kelebihan dan kekurangan layanan ngrok agar sesuai dengan perancangan sistem yang telah dibuat.

\subsection{Implementasi}

Berikut ini adalah implementasi atau pelaksanaan pengaksesan menggunakan ngrok pada sistem yang telah dibuat sebelumnya :

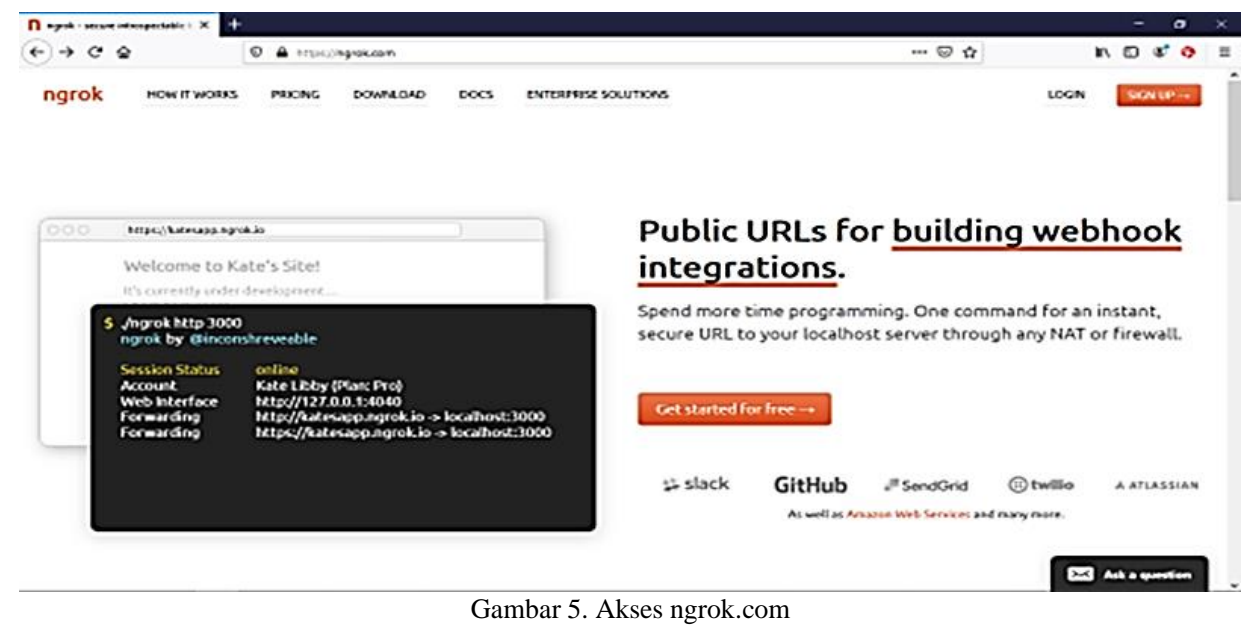

Gambar 5 adalah ilustrasi akses website ngrok, setelah itu lakukan registrasi akun untuk

mendapatkan autentikasi token yang digunakan untuk login. 


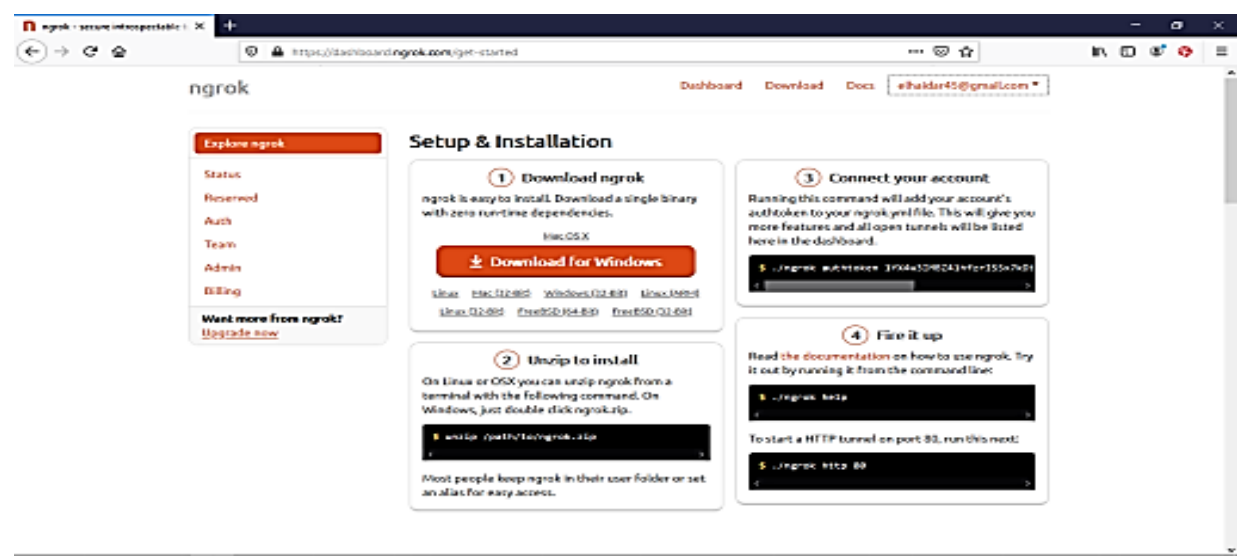

Gambar 6. Tampilan halaman get-started ngrok.com

Gambar 6 adalah tampilan utama website ngrok. Dianjurkan untuk mendownload aplikasi ngrok yang sesuai dengan spesifikasi perangkat, yang menjadi server lokal, sistem operasi untuk mendukung pengaksesan.

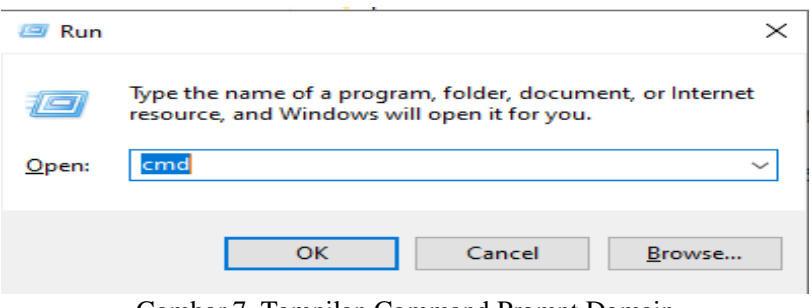

Gambar 7. Tampilan Command Prompt Domain

Langkah selanjutnya, membuka cmd pada windows dengan menggunakan kombinasi tombol "windows + R" seperti pada Gambar 7. Kemudian ketikkan cmd pada kotak dialog.

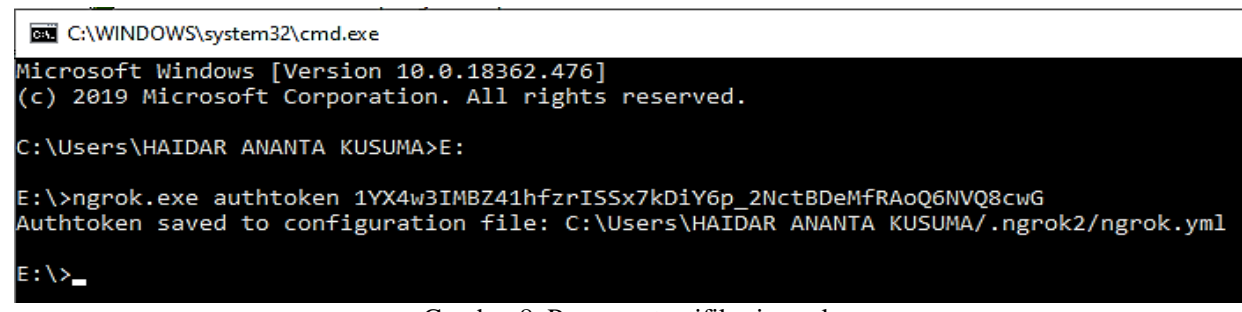

Gambar 8. Proses autentifikasi ngrok

Gambar 8 adalah tampilan cmd, untuk mengakses direktori penyimpanan file ngrok yang telah diunduh dan melakukan proses autentikasi token dengan cara ketikkan perintah "ngrok.exe authtoken (masukkan kode token yang didapat pada website ngrok)".

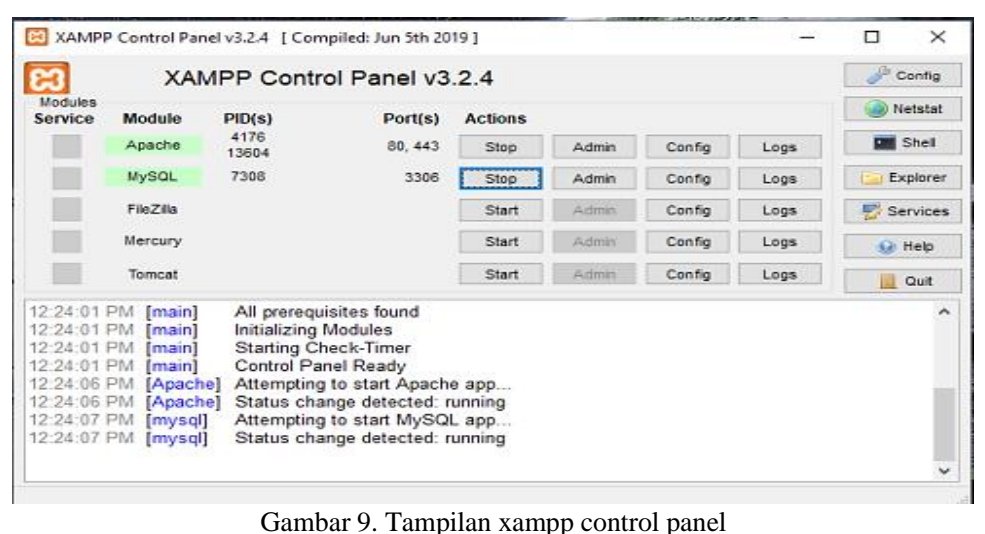

Gambar 9 adalah pengaktifkan Apache dan MySQL server dengan cara mengklik tombol 'start' pada XAMPP control panel. 


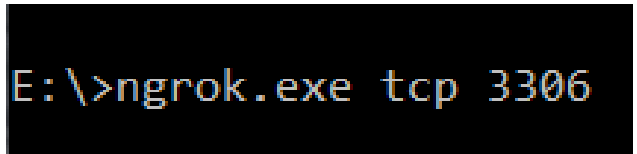

Gambar 10. Expose port SSH

Gambar 10 adala perintah dalam command prompt domain untuk menjalankan ngrok dengan mengekspose SSH pada windows dengan port mysql

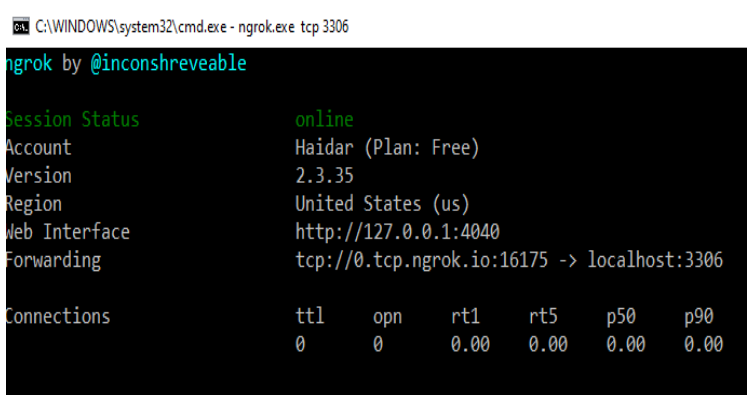

Gambar 11. Output tunnel port SSH

Setelah mengakses perintah pada Gambar 10 didapatkan keluaran yang berupa public URL yang digunakan untuk mengakses ngrok seperti yang ditampilkan pada Gambar 11. Pada gambar tersebut ditampilkan beberapa informasi, seperti nama akun, versi ngrok yang digunakan, region, web interface, forwading (URL untuk mengakses web secara online), dan keterangan koneksi.

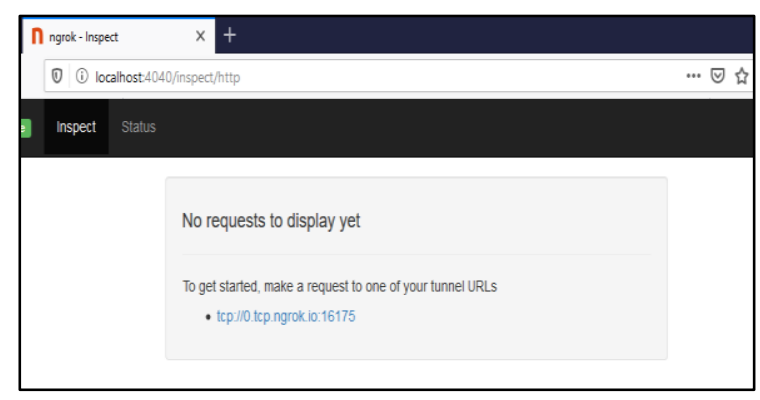

Gambar 12. Output public URL

Gambar 12 adalah tampilan untuk mulai melakukan layanan ngrok, dan membuat permintaan tunnel URL. URL tersebut akan digunakan pada untuk koneksi mysql

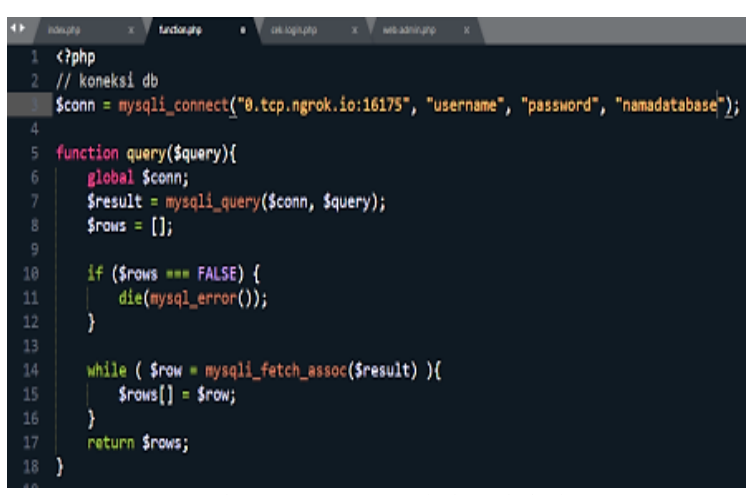

Gambar 13. Source code koneksi php

Penambahan forwarding IP address ngrok pada source code koneksi php untuk memberikan akses ke database yang telah dibuat.

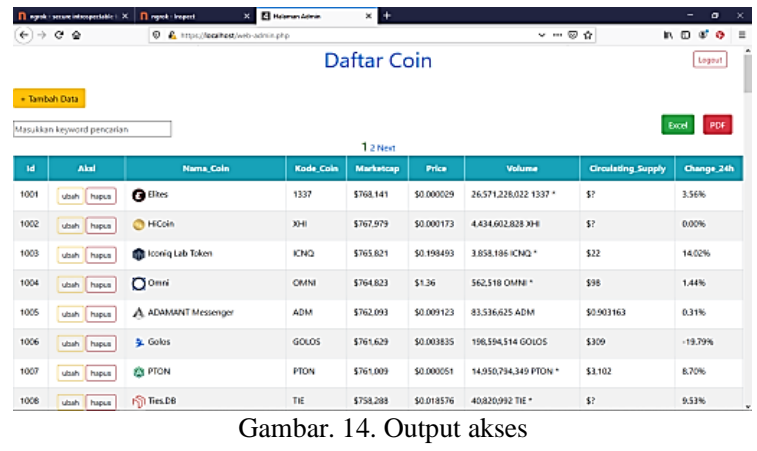

Gambar 14 adalah tampilan situs web yang telah tersambung dengan database dan telah diakses menggunakan ngrok. Dari mulai langkah awal pengaksesan dan mendapatkan token, tunnel url serta ip address yang digunakan untuk mengakses web server dan mysql sehingga pada saat mengakses

website dengan database yang berada pada komputer lain bisa dilakukan dengan mudah dan lebih efisien.

Berdasarkan percobaan yang telah kami lakukan dapat dijelaskan mengenai kelebihan dan kekurangan pada layanan ngrok dalam mengakses database mysql dan web server yang secara detail akan dibahas pada Tabel 1 .

Tabel 1. Kelebihan dan Kekurangan Penggunaan Ngrok

\begin{tabular}{|c|c|}
\hline & In \\
\hline $\begin{array}{l}\text { Dapat dijadikan } \\
\text { alternatif untuk } \\
\text { mengembangkan } \\
\text { web tanpa layana } \\
\text { hosting. }\end{array}$ & $\begin{array}{l}\text { Output URL yang } \\
\text { berubah-ubah setiap kali } \\
\text { restart. }\end{array}$ \\
\hline $\begin{array}{l}\text { Konfigurasi atau } \\
\text { instalasi mudah. }\end{array}$ & $\begin{array}{l}\text { Komputer harus } \begin{array}{r}\text { selalu } \\
\text { terkoneksi }\end{array} \\
\text { internet. }\end{array}$ \\
\hline $\begin{array}{l}\text { Forwarding } \\
\text { dilakukan } \\
\text { otomatis. }\end{array}$ & $\begin{array}{l}\text { Perlu dilakukan setting } \\
\text { ulang pada perangkat } \\
\text { server mati atau pada saat } \\
\text { mengalami restart. }\end{array}$ \\
\hline
\end{tabular}

\section{KESIMPULAN}

Berdasarkan tujuan penelitian dan hasil beserta pembahasan diperoleh beberapa kesimpulan yaitu a). Database MySQL dan Web server local dapat diakses oleh publik/pengguna lain yang memiliki link url melalui jaringan internet . b). Database MySQL dan Web server local dapat diakses menggunakan url yang disediakan oleh ngrok setelah forwarding ip address pada server ngrok. c). Ngrok dapat digunakan sebagai alternatif dalam pengembangan web server tanpa layanan hosting.

Adapun beberapa hal yang perlu diperhatikan dalam menggunakan layanan ngrok yaitu a). Perlu diperhatikan untuk mengecek alamat ip pada computer terlebih dahulu. b). Memastikan bahwa komputer terhubung dengan internet. c) 
Mengkonfigurasikan dan memastikan port yang digunakan pada web server lokal dan MySQL.

\section{DAFTAR PUSTAKA}

[1] A. M. Saeed., 2017. 'Role of Database Management Systems (DBMS) in Supporting Information Technology in Sector of Education,' Int. J. Sci. Res., vol. 6. no. 5, pp. 1462-1466.

[2] A. Tedyyana and Kurniati, R., 2016. 'Membuat Web Server Menggunakan Dinamic Domain', $J$. Teknol. Inf. Komun. Digit. Zo., vol. 7. no. 1, pp. $1-10$.

[3] P. S. Hasugian., 2018. 'Perancangan Website Sebagai Media Promosi dan Informasi', $J$. Inform. Pelita Nusant., vol. 3, pp. 82-86.

[4] A. Firman., H. F. Wowor dan X. Najoan., 2016 'Sistem Informasi Perpustakaan Online Berbasis Web', E-Journal Teknologi Elektro Dan Komputer, vol. 5. no. 2, pp. 29-36.

[5] R. Harminingtya., 2014. 'analisis layanan website sebagai media promosi, media transaksi dan media informasi dan pengaruhnya terhadap brand image perusahaan pada hotel ciputra di kota semarang', Jurnal STIE semarang, vol. 6, pp. 37-57.

[6] F. A. Batubara., 2015. 'Perancangan Website Pada Pt . Ratu Enim Palembang', Jurnal ILMU Pengetahuan DAN Teknologi Terapan REINTEK, vol. 7. no. 1, pp. 35-57.

[7] A. Y. Putra., H. Srihendayana and N. Tjahjamooniarsih, N., 2015. 'Monitoring Kamera Pengintai Jarak Jauh Terintegrasi dengan Google Drive Berbasis Raspberry Pi Via Internet', Jurnal Teknik Elektro Universitas Tanjungpura, pp. 1-7.

[8] D. Ghorpade., S. Jadhav., S. Gunjal., S. Bogir, and P. S. Tambe., 2019. 'survey on intelligent system for college', International Research Journal of Engineering and Technology (IRJET), vol. 6. no. 10, pp. 1744-1745.

[9] D. Lavarino and W. Yustanti., 2016. 'Rancang Bangun E - Voting Berbasis Website di Universitas Negeri Surabaya', Jurnal Manajemen Informatika, vol. 6, pp. 72-81.

[10] A. Prayitno. and Safitri, Y., (2015) 'Pemanfaatan Sistem Informasi Perpustakaan Digital Berbasis Website Untuk Para Penulis', IJSE - Indonesian Journal on Software Engineering, vol. 1, pp. 1-10.

[11] A. Hidayati., 2013. 'Perancangan dan Pembuatan Aplikasi Pendaftaran Mahasiswa Baru', Jurnal ELTEK, vol. 11, pp. 67-78.

[12] S. Hadiyatullah., (2019) 'Rancang Bangun Sistem Untuk Melatih Kicauan Burung Cendet Berbasis Raspberry Pi," in Disertasi Doktoral, Institut Teknologi Nasional Malang.

[13] B. Prasetyo., T. J. Pattiasina and A. N. Soetarmono., (2015) 'Perancangan dan Pembuatan Sistem Informasi Gudang (Studi
Kasus: PT. PLN (Persero) Area Surabaya Barat)', Teknika, 4(1), pp. 12-16.

[14] A. J. Mustafa., A. Mubarak., and Rosihan, 2018. 'Sistem Informasi Geografis Pencarian Lokasi Bank dan ATM dikota Ternate Berbasis Web', JIKO - Jurnal Informasi dan Komputer, vol. 2, pp. $48-55$.

[15] A. Mubarak., (2019) 'Rancang Bangun Aplikasi Web Sekolah Menggunakan UML (Unified Modeling Language) dan Bahasa Pemrograman PHP (PHP Hypertext Preprocessor) Berorientasi Objek', JIKO (Jurnal Informatika dan Komputer). vol. 02, pp. 19-25.

[16] R. Womboo., M. Jamil., and Rosihan, (2019) 'sistem informasi geofisika di stasiun geofisika kelas III ternate berbasis web', Jurnal Informasi dan Komputer, vol. 2, pp. 73-80.

[17] O. A. John., O. O. Anthony and S. Emmanuel., 2019. 'A Novel Real-Time Online Payment Platform for E-commerce Website Running on Local Machine', International Journal Informatic Communication Science, pp. 1-6. 